\title{
The glucose ketone index calculator: a simple tool to monitor therapeutic efficacy for metabolic management of brain cancer
}

\author{
Joshua J Meidenbauer, Purna Mukherjee and Thomas N Seyfried ${ }^{*}$
}

\begin{abstract}
Background: Metabolic therapy using ketogenic diets (KD) is emerging as an alternative or complementary approach to the current standard of care for brain cancer management. This therapeutic strategy targets the aerobic fermentation of glucose (Warburg effect), which is the common metabolic malady of most cancers including brain tumors. The KD targets tumor energy metabolism by lowering blood glucose and elevating blood ketones ( $\beta$-hydroxybutyrate). Brain tumor cells, unlike normal brain cells, cannot use ketone bodies effectively for energy when glucose becomes limiting. Although plasma levels of glucose and ketone bodies have been used separately to predict the therapeutic success of metabolic therapy, daily glucose levels can fluctuate widely in brain cancer patients. This can create difficulty in linking changes in blood glucose and ketones to efficacy of metabolic therapy.
\end{abstract}

Methods: A program was developed (Glucose Ketone Index Calculator, GKIC) that tracks the ratio of blood glucose to ketones as a single value. We have termed this ratio the Glucose Ketone Index (GKI).

Results: The GKIC was used to compute the GKI for data published on blood glucose and ketone levels in humans and mice with brain tumors. The results showed a clear relationship between the GKI and therapeutic efficacy using ketogenic diets and calorie restriction.

Conclusions: The GKIC is a simple tool that can help monitor the efficacy of metabolic therapy in preclinical animal models and in clinical trials for malignant brain cancer and possibly other cancers that express aerobic fermentation.

Keywords: Glucose, Beta-hydroxybutyrate, Calorie restriction, Metabolic therapy, Glioblastoma, Warburg effect, Ketogenic diet, Ketone bodies

\section{Introduction}

Dietary therapy using ketogenic diets is emerging as an alternative or complementary approach to the current standard of care for brain cancer management. Prognosis remains poor for malignant gliomas in both children and adults [1-5]. Although genetic heterogeneity is extensive in malignant gliomas [6-8], the Warburg effect (aerobic fermentation of glucose) is a common metabolic malady expressed in nearly all neoplastic cells of these and other malignant tumors [9-11]. Aerobic fermentation (Warburg effect) is necessary to compensate for the insufficiency of mitochondrial oxidative phosphorylation in the cells of most tumors [9,12-14]. Mitochondrial structure and function is abnormal in malignant gliomas from both

* Correspondence: thomas.seyfried.1@bc.edu

Biology Department, Boston College, Chestnut Hill, MA 02467, USA mice and humans [15-19]. Normal brain cells gradually transition from the metabolism of glucose to the metabolism of ketone bodies (primarily $\beta$-hydroxybutyrate and acetoacetate) for energy when circulating glucose levels become limiting [20,21]. Ketone bodies are derived from fatty acids in the liver and are produced to compensate for glucose depletion during periods of food restriction [20]. Ketone bodies bypass the glycolytic pathway in the cytoplasm and are metabolized directly to acetyl CoA in the mitochondria [22]. Tumor cells are less capable than normal cells in metabolizing ketone bodies for energy due to their mitochondrial defects [2,12,23].

Therapies that can lower glucose and elevate ketone bodies will place more energy stress on the tumor cells than on the normal brain cells [12,24]. This therapeutic strategy is illustrated conceptually in Figure 1, as we 


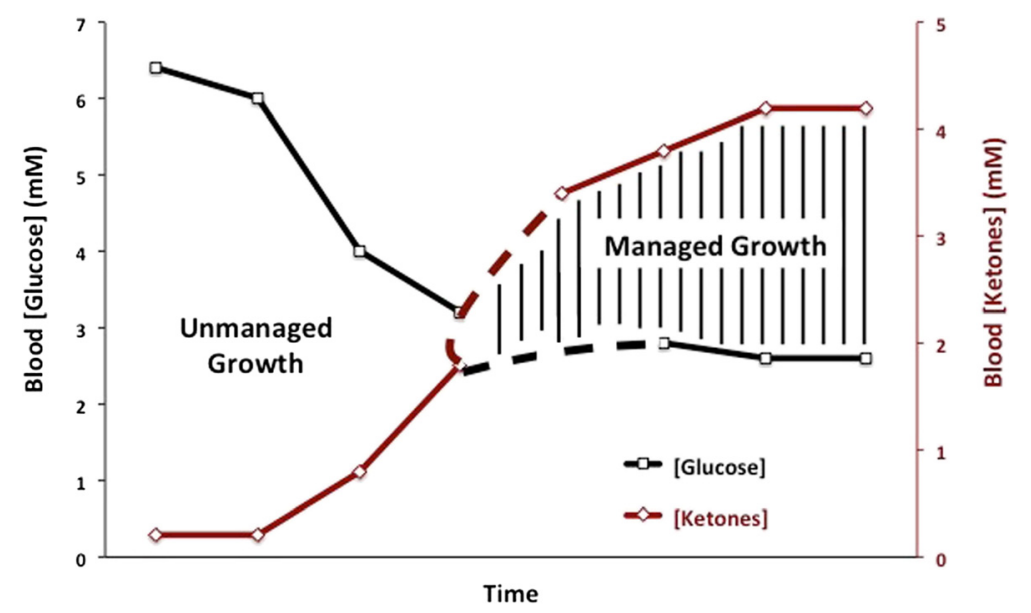

Figure 1 Relationship of plasma glucose and ketone body levels to brain cancer management. The glucose and ketone ( $\beta$-OHB) values are within normal physiological ranges under fasting conditions in humans. We refer to this state as the zone of metabolic management. As blood glucose falls and blood ketones rise, an individual is predicted to reach the zone of metabolic management. Tumor progression is predicted to be slower within the metabolic target zone than outside of the zone. This can be tracked utilizing the Glucose Ketone Index. The dashed lines signify the variability that could exist among individuals in reaching a GKI associated with therapeutic efficacy.

previously described [25]. However, daily activities and emotional stress can cause blood glucose levels to vary making it difficult for some people to enter the predicted zone of metabolic management [26]. A more stable measure of systemic energy metabolism is therefore needed to predict metabolic management of tumor growth. The ratio of blood glucose to blood ketone bodies $\beta$-hydroxybutyrate $(\beta-\mathrm{OHB})$ is a clinical biomarker that could provide a better indication of metabolic management than could measurement of either blood glucose or ketone body levels alone.

\section{Methods}

The 'Glucose Ketone Index' (GKI) was created to track the zone of metabolic management for brain tumor management. The GKI is a biomarker that refers to the molar ratio of circulating glucose over $\beta-\mathrm{OHB}$, which is the major circulating ketone body. A mathematical tool called the Glucose Ketone Index Calculator (Additional file 1) was developed that can calculate the GKI and monitor changes in this parameter on a daily basis (Equation 1). The GKIC generates a single value that can assess the relationship of the major fermentable tumor fuel (glucose) to the non-fermentable fuel (ketone bodies). Because many commercial blood glucose monitors give outputs in $\mathrm{mg} / \mathrm{dL}$, rather than millimolar (mM), the GKIC converts the units to millimolar. Included in the program is a unit converter for both glucose and ketones $(\beta-\mathrm{OHB})$, which can convert glucose and ketone values from $\mathrm{mg} / \mathrm{dL}$ to $\mathrm{mM}$ and from $\mathrm{mM}$ to $\mathrm{mg} / \mathrm{dL}$ (Equations 2, 3, 4, 5). The molecular weights used for calculations in the GKIC are $180.16 \mathrm{~g} / \mathrm{mol}$ for glucose and $104.1 \mathrm{~g} / \mathrm{mol}$ for $\beta-\mathrm{OHB}$, which is the major circulating ketone body measured in most commercial testing kits. The unit converter allows for compatibility for a variety of glucose and ketone testing monitors.

$$
\frac{[\text { Glucose Ketone Index }]=[\text { Glucose }(\mathrm{mg} / \mathrm{dL})] /{ }_{18.016}\left(\mathrm{~g} * \frac{\mathrm{dL}}{\mathrm{mol}}\right)}{[\text { Ketone }(\mathrm{mM})]}
$$

$\begin{aligned} {[\operatorname{Glucose}(\mathrm{mg} / \mathrm{dL})]=} & {[\text { Glucose }(\mathrm{mM})] } \\ & \times 18.016\left(\mathrm{~g} * \frac{\mathrm{dL}}{\mathrm{mol}}\right)\end{aligned}$

$$
\begin{aligned}
{[\text { Glucose }(\mathrm{mM})]=\frac{[\text { Glucose }(\mathrm{mg} / \mathrm{dL})]}{18.016\left(\mathrm{~g} * \frac{\mathrm{dL}}{\mathrm{mol}}\right)} } \\
\begin{aligned}
{[\text { Ketone }(\mathrm{mg} / \mathrm{dL})]=} & {[\text { Ketone }(\mathrm{mM})] } \\
& \times 10.41\left(\mathrm{~g} * \frac{\mathrm{dl}}{\mathrm{mol}}\right)
\end{aligned}
\end{aligned}
$$

$[$ Ketone $(\mathrm{mM})]=\frac{[\text { Ketone }(\mathrm{mg} / \mathrm{dL})]}{10.41\left(\mathrm{~g} * \frac{\mathrm{dl}}{\mathrm{mol}}\right)}$

The GKIC can set a target GKI value to help track therapeutic status. Daily GKI values can be plotted to allow visual tracking of progress against an initial index value over monthly periods. Entrance into the zone of metabolic management would be seen as the GKI value falls below the set target value (as illustrated in Figure 2). Additionally, the GKIC can track the number of days that an individual falls within the predicted target zone.

\section{Results}

The GKIC was used to estimate the GKI for humans and mice with brain tumors that were treated with either calorie restriction or ketogenic diets from five previously 


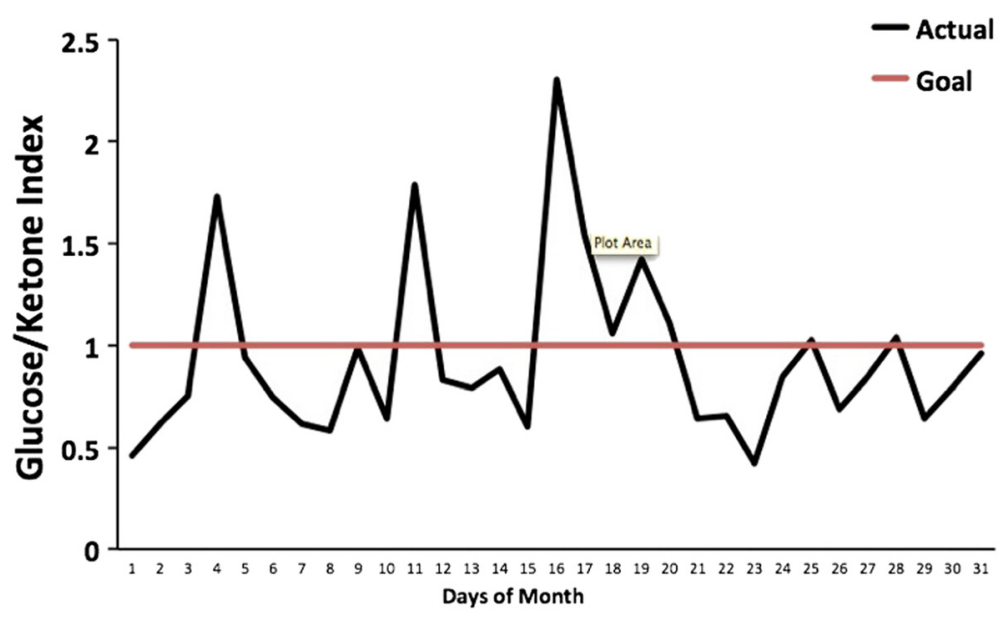

Figure 2 The Glucose Ketone Index Calculator tracking an individual's GKI. The individual glucose and ketone values are displayed, along with the corresponding GKI values. The GKI values are plotted over the course of a month (black line), whereas the GKI target value (1.0) is plotted as a red line. We consider GKI values approaching 1.0 as potentially most therapeutic.

published reports (Table 1). The first clinical study evaluated two pediatric patients; one with an anaplastic astrocytoma, and another with a cerebellar astrocytoma [27]. Both individuals were placed on a ketogenic diet for eight weeks. During the 8-week treatment period, GKI dropped from about 27.5 to about $0.7-1.1$ in the patients. The patient with the anaplastic astrocytoma, who did not have a response to prior chemotherapy, had a $21.7 \%$ reduction in fluorodeoxyglucose uptake at the tumor site (no chemotherapy during diet). The patient with the cerebellar astrocytoma received standard chemotherapy concomitant with the ketogenic diet. Fluorodeoxyglucose uptake at the tumor site in this patient was reduced by $21.8 \%$. Quality of life was markedly improved in both children after initiation of the KD [27].

The second clinical study evaluated a 65-yr-old woman with glioblastoma multiforme [28]. The patient was placed on a calorie-restricted ketogenic diet $(600 \mathrm{kcal} /$ day) concomitant with standard chemotherapy and radiation, without dexamethasone, for eight weeks. The patient's GKI decreased from 37.5 to 1.4 in the first three weeks of the diet. No discernible brain tumor tissue was detected with MRI in the patient at the end of eight weeks of the calorie restricted ketogenic diet. It is also important to mention that the patient was free of symptoms while she adhered to the KD. Tumor recurrence occurred 10 weeks after suspension of the ketogenic diet.

The third study, a preclinical mouse study, evaluated the effects of diets on an orthotopically implanted CT$2 \mathrm{~A}$ syngeneic mouse astrocytoma in C57BL/6 J mice [29]. Mice were implanted with tumors and fed one of four diets for 13 days: 1) standard diet fed unrestricted, 2) calorie restricted standard diet, 3) ketogenic diet fed unrestricted, or 4) calorie restricted ketogenic diet. The mice fed a standard unrestricted diet and a ketogenic diet had rapid tumor growth after 13 days, and a GKI of 15.2 and 11.4, respectively. The group fed a calorie restricted standard diet had a significant decrease in tumor volume after 13 days, along with a GKI of 3.7. The group fed a calorie restricted ketogenic diet also had a significant decrease in tumor volume, along with a GKI of 4.4.

The fourth study evaluated the effects of diets on an orthotopically implanted CT-2A syngeneic mouse astrocytoma in C57BL/6 J mice and an orthotopically implanted human U87-MG human xenograft glioma in BALBc/6-severe combined immunodeficiency (SCID) mice [30]. Tumors were implanted and grown in the mice for three days prior to diet initiation. After three days, mice were maintained on one of three diets for 8 days: 1 ) standard diet fed unrestricted, 2) ketogenic diet fed unrestricted, or 3) calorie restricted ketogenic diet. Tumor weights at the end of 8 days were reduced only in the mice that were fed a calorie restricted diet and experienced a significant decrease in GKI. Groups of mice that did not have a reduction in tumor weight had GKI's that ranged from 9.6 - 70.0. The groups of mice that had a reduction in tumor weight had GKI's that ranged from $1.8-4.4$.

The fifth study evaluated the effects of diet and radiation on mouse GL261 glioma implanted intracranially in albino C57BL/6 J mice [31]. The mice were implanted with tumors, and three days later they were placed on either a standard diet fed unrestricted or a ketogenic diet fed unrestricted. Mice were also assigned to groups that either received or did not receive concomitant radiation therapy. Without radiation, mice that were fed a ketogenic diet had a GKI of 6.4 and had a median survival of 28 days, compared to a GKI of 50.0 and median survival of 23 days for the standard diet group. With radiation, mice that were fed a ketogenic diet had a GKI of 5.7 and a median survival of $200+$ days, compared to a GKI of 
Table 1 Low Glucose Ketone Index values are related to improved prognoses in humans and mice with brain tumors

\begin{tabular}{|c|c|c|c|c|c|c|c|c|}
\hline Subjects & Tumor type & Diet & $\begin{array}{l}\text { \# of } \\
\text { subjects }\end{array}$ & $\begin{array}{l}\text { Days on } \\
\text { diet }\end{array}$ & $\begin{array}{l}\text { Glucose } \\
\text { (mM) }\end{array}$ & $\begin{array}{l}\text { Ketones }^{f} \\
(\mathrm{mM})\end{array}$ & $\begin{array}{l}\text { Glucose Ketone } \\
\text { Index }\end{array}$ & Prognosis \\
\hline \multirow[t]{5}{*}{ Human' } & \multirow[t]{2}{*}{ Anaplastic Astrocytoma } & \multirow[t]{2}{*}{$K D-U R^{a}$} & \multirow[t]{2}{*}{1} & 0 & 5.5 & 0.2 & 27.5 & $\begin{array}{l}\text { No response to standard } \\
\text { chemotherapy }\end{array}$ \\
\hline & & & & 56 & 5.0 & 4.6 & 1.1 & $\begin{array}{l}\text { FDG uptake at tumor site was } \\
\text { decreased by } 21.77 \% \text {; tumor } \\
\text { margins were unchanged }\end{array}$ \\
\hline & \multirow[t]{3}{*}{ Cerebellar Astrocytoma } & \multirow[t]{3}{*}{$\mathrm{KD}-\mathrm{UR}$} & \multirow[t]{3}{*}{1} & 0 & 5.5 & 0.2 & 27.5 & $\begin{array}{l}\text { Tumor resected and initiated on } \\
\text { KD while under standard } \\
\text { chemotherapy,after tumor was } \\
\text { radiologically stable by } \mathrm{CT}\end{array}$ \\
\hline & & & & \multirow[t]{2}{*}{56} & \multirow[t]{2}{*}{4.0} & \multirow[t]{2}{*}{5.5} & \multirow[t]{2}{*}{0.7} & $\begin{array}{l}\text { FDG uptake at tumor site was } \\
\text { decreased by } 21.84 \%\end{array}$ \\
\hline & & & & & & & & $\begin{array}{l}\text { Notes: Both patients remained in } \\
\text { remission after return to standard } \\
\text { diet for } 5 \text { years (Subject 1) and } \\
4 \text { years (Subject 2),at time of } \\
\text { publication }\end{array}$ \\
\hline \multirow[t]{4}{*}{ Human $^{2}$} & \multirow[t]{4}{*}{ Glioblastoma } & \multirow[t]{4}{*}{$K D-R^{b}$} & \multirow[t]{4}{*}{1} & 0 & 7.5 & $0.2^{9}$ & 37.5 & \multirow{2}{*}{$\begin{array}{l}\text { Incomplete surgical resection of } \\
\text { tumor; received chemotherapy } \\
\text { and radiation therapy concurrent } \\
\text { with diet }\end{array}$} \\
\hline & & & & 21 & 3.5 & $2.5^{9}$ & 1.4 & \\
\hline & & & & & & & & $\begin{array}{l}\text { No evidence of tumor by MRI } \\
\text { after concurrent therapy }\end{array}$ \\
\hline & & & & & & & & $\begin{array}{l}\text { Notes: Patient stayed on low } \\
\text { calorie diet for an additional } \\
5 \text { months; tumor recurrence } \\
3 \text { months after low-calorie diet } \\
\text { suspension }\end{array}$ \\
\hline \multirow[t]{4}{*}{ Mouse $^{3}$} & Mouse CT-2A astrocytoma & SD-UR & 7 & 13 & 9.1 & 0.6 & 15.2 & Tumor dry weight:55 $\pm 15 \mathrm{mg}^{\mathrm{h}}$ \\
\hline & \multirow[t]{3}{*}{ Syngenic (C57BL/6 J) } & $S D-R^{d}$ & 6 & 13 & 5.2 & 1.4 & 3.7 & Tumor dry weight:7 $\pm 7 \mathrm{mg}$ \\
\hline & & $\mathrm{KD}-\mathrm{UR}$ & 14 & 13 & 11.4 & 1.0 & 11.4 & Tumor dry weight:70 $\pm 15 \mathrm{mg}$ \\
\hline & & KD-R & 6 & 13 & 5.7 & 1.3 & 4.4 & Tumor dry weight:14 \pm 8 mg \\
\hline \multirow[t]{6}{*}{ Mouse $^{4}$} & Mouse CT-2A astrocytoma & SD-UR & $12-14$ & 8 & 14.0 & 0.2 & 70.0 & Tumor dry weight: $95 \pm 25 \mathrm{mg}^{\mathrm{h}}$ \\
\hline & \multirow[t]{2}{*}{ Syngenic (C57BL/6 J) } & KD-UR & $12-14$ & 8 & 13.5 & 0.6 & 22.5 & Tumor dry weight:90 \pm 15 mg \\
\hline & & $\mathrm{KD}-\mathrm{R}$ & $12-14$ & 8 & 8.0 & 1.8 & 4.4 & Tumor dry weight:35 \pm 5 mg \\
\hline & Human U87-MG glioma & SD-UR & $12-14$ & 8 & 11.5 & 0.5 & 23.0 & Tumor dry weight: $60 \pm 10 \mathrm{mg}^{\mathrm{h}}$ \\
\hline & \multirow[t]{2}{*}{ Xenograft (SCID) } & KD-UR & $12-14$ & 8 & 11.5 & 1.2 & 9.6 & Tumor dry weight: $60 \pm 7 \mathrm{mg}$ \\
\hline & & $\mathrm{KD}-\mathrm{R}$ & $12-14$ & 8 & 5.5 & 3.0 & 1.8 & Tumor dry weight:37 \pm 5 mg \\
\hline \multirow[t]{4}{*}{ Mouse $^{5}$} & Mouse GL261 glioma & SD-UR & 19 & 13 & 10.0 & 0.2 & 50.0 & Median survival time:23 days \\
\hline & \multirow[t]{3}{*}{ (C57BL/6-cBrd/cBrd/Cr) } & KD-UR & 19 & 13 & 8.9 & 1.4 & 6.4 & Median survival time:28 days \\
\hline & & $\mathrm{SD}-U \mathrm{R}+\mathrm{Rad}^{\mathrm{e}}$ & 11 & 13 & 9.7 & 0.3 & 32.3 & Median survival time:41 days \\
\hline & & KD-UR + Rad & 11 & 13 & 9.7 & 1.7 & 5.7 & Median survival time:200 + days \\
\hline
\end{tabular}

${ }^{1}$ Nebeling et al., 1995 [27]

2Zuccoli et al., 2010 [28]

${ }^{3}$ Seyfried et al., 2003 [29]

${ }^{4}$ Zhou et al., 2007 [30]

${ }^{5}$ Abdelwahab et al., 2012 [31]

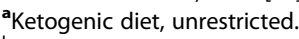

${ }^{b}$ Ketogenic diet, restricted.

c Standard diet, unrestricted.

d Standard diet, restricted.

e Diet with radiation therapy.

${ }^{f}$ Blood/plasma beta-hydroxybutyrate measurement.

${ }^{g}$ Urinary ketones were measured.

${ }^{\mathrm{h}}$ Mean $\pm 95 \%$ Confidence Interval. 
32.3 and median survival of 41 days for the standard diet group.

In addition to these studies, Table 2 shows a clear association of the GKI to the therapeutic action of calorie restriction against distal invasion, proliferation, and angiogenesis in the VM-M3 model of glioblastoma. The data for the GKI in Table 2 was computed from those mice that were measured for both glucose and ketones in comparison with the other biomarkers as previously described [32]. When viewed collectively, the results from the published reports show a clear relationship between the GKI and efficacy of metabolic therapy using either the KD or calorie restriction. Therapeutic efficacy of the KD or calorie restriction is greater with lower GKI values than with higher values. The results suggest that GKI levels that approach 1.0 are therapeutic for managing brain tumor growth. Further studies will be needed to determine those GKI values that can most accurately predict efficacy during metabolic therapy involving diet or procedures that lower glucose and elevate ketone bodies.

\section{Discussion}

We present evidence showing that the GKI can predict success for brain cancer management in humans and mice using metabolic therapies that lower blood glucose and elevate blood ketone levels. Besides ketogenic diets, other dietary therapies, such as calorie restriction, low carbohydrate diets, and therapeutic fasting, can also lower blood glucose and elevate $\beta$-OHB levels and can have anti-tumor effects [24,33-38]. The GKIC was developed to more reliably and simply predict therapeutic management for brain cancer patients under these dietary states than could measurements of either blood glucose or ketones alone. The data presented in Tables 1 and 2 support this prediction. Although the GKI is simple in concept, it has not been used previously to gage success of various metabolic therapies based on inverse changes in glucose and ketone body metabolism.

As brain tumor cells are dependent on glucose for survival and cannot effectively use ketone bodies as an alternative fuel, a zone of metabolic management can be achieved under conditions of low glucose and elevated ketones. Ketone bodies also prevent neurological symptoms associated with hypoglycemia, such as neuroglycopenia, which allows blood glucose levels to be lowered even further [22,39]. Hence, ketone body metabolism can protect normal brain cells under conditions that target tumor cells [40]. The zone of metabolic management is considered the therapeutic state that places maximal metabolic stress on tumor cells while protecting the health and vitality of normal cells [41]. We have presented substantial data showing that the GKI is validated in several studies in mice. We feel that prospective validation of the GKIC will be obtained from future studies using ketogenic diet therapy in humans with brain cancer and possibly other cancers that cannot effectively metabolize $\beta$-OHB for energy, and depend upon glucose for survival.

The GKI can be useful in determining the success of dietary therapies that shift glucose- and lactate-based metabolism to ketone-based metabolism. As a shift toward ketone-based metabolism underscores the utility of many dietary therapies in treating metabolic diseases $[41,42]$, the GKI can be used in determining the therapeutic success of shifting metabolism in individual patients. The GKI therefore can be used to study the effectiveness of dietary therapy in clinical trials of patients under a range of dietary conditions, with a composite primary endpoint consisting of lowering the subjects' GKI. This will allow investigators to parse the effects of successful dietary intervention on disease outcome from unsuccessful dietary intervention.

Recent clinical studies assessing the effects of dietary therapy on brain cancer progression have not measured both blood glucose and ketone bodies throughout the study periods [43,44]. Future clinical studies that intend to assess the effect of dietary therapy on brain tumor progression should measure both blood glucose and ketone, as these markers are necessary to connect dietary therapy to therapeutic efficacy. Preclinical studies have demonstrated a clear linkage between GKI and therapeutic efficacy. The GKI will be an important biomarker to measure in future rigorously designed and powered clinical studies in order to demonstrate if there is a linkage between GKI and therapeutic efficacy, as the few case reports in the literature suggest.

The zone of metabolic management is likely entered with GKI values between 1 and 2 for humans. Optimal management is predicted for values approaching 1.0, and blood glucose and ketone values should be measured 2-3 hours postprandial, twice a day if possible. This will allow individuals to connect their dietary intake to changes in their GKI. As an example, Figure 2 uses

Table 2 Linking the Glucose Ketone Index (GKI) to the therapeutic action of calorie restriction against distal invasion, proliferation, and angiogenesis in the VM-M3 model of glioblastoma

\begin{tabular}{|c|c|c|c|c|c|c|}
\hline Treatment & Glucose (mM) & Ketone (mM) & GKI & Distal invasion (photons/sec) & Proliferation (Ki67 \%) & Angiogenesis (vessels/hpf) \\
\hline$A L$ & $11.2 \pm 0.6$ & $0.7 \pm 0.09$ & $15.3 \pm 0.9$ & $14 \pm 1.8$ & $48 \pm 1.2$ & $15 \pm 1.1$ \\
\hline CR & $8.3 \pm 0.8$ & $1.32 \pm 0.1$ & $6.5 \pm 0.9$ & $6 \pm 0.9$ & $34 \pm 1.5$ & $7 \pm 0.72$ \\
\hline
\end{tabular}

$\mathrm{AL}$, ad libitum feeding and CR is $60 \%$ food reduction for 10 days. Values are Mean \pm SEM. 3-7 mice were evaluated in each group; hpf, high power field. 
the GKIC to track the GKI values of an individual on a ketogenic diet, with a target GKI of 1.0. When an individual's GKI falls below the line denoting the target metabolic state, the zone of metabolic management is achieved. Further studies will be needed to establish the validity of the predicted zone of management.

It has not escaped our attention that the GKIC could have utility not only for managing brain cancer and possibly other cancers dependent on glucose and aerobic fermentation for survival, but also for managing other diseases or conditions where the ratio of glucose to ketone bodies could be therapeutic. Such diseases and conditions include Alzheimer's disease, Parkinson's disease, traumatic brain injury, chronic inflammatory disease, and epilepsy [41]. For example, the ketogenic diet has long been recognized as an effective therapeutic strategy for managing refractory seizures in children [45,46]. Therapeutic success in managing generalized idiopathic epilepsy in epileptic EL mice can also be seen when applying the GKI to the data presented on glucose and $\beta$ OHB [47]. Healthy individuals can utilize the GKIC to prevent diseases and disorder, and manage general wellness. Further studies will be needed to determine the utility of the GKIC for predicting therapeutic success in the metabolic management of disease.

\section{Additional file}

Additional file 1: Instructions for calculating the GKI using a blood glucose and ketone monitor.

\section{Competing interests}

The authors declare that they have no competing interests.

\section{Authors' contributions}

JM and TNS developed the Glucose/Ketone Index Calculator and wrote the paper together. PM provided the data for Table 2 and helped with editing and data presentation. All authors read and approved the final manuscript.

\section{Acknowledgements}

This work was supported, in part, by the National Institutes of Health (HD-39722, NS-55195 and (A-102135), a grant from the American Institute of Cancer Research, and the Boston College Expense Fund (TNS). Authors would like to thank Madam Trudy Dupont for providing us with valuable data to develop the GKIC.

Received: 19 November 2014 Accepted: 24 February 2015

Published online: 11 March 2015

\section{References}

1. Fisher PG, Buffler PA. Malignant gliomas in 2005: where to GO from here? JAMA. 2005;293:615-7.

2. Seyfried TN, Marsh J, Mukherjee P, Zuccoli G, D'Agostino DP. Could metabolic therapy become a viable alternative to the standard of care for managing glioblastoma? US Neurology. 2014;10:48-55.

3. Armstrong GT, Phillips PC, Rorke-Adams LB, Judkins AR, Localio AR, Fisher MJ. Gliomatosis cerebri: 20 years of experience at the Children's Hospital of Philadelphia. Cancer. 2006;107:1597-606.

4. Artico M, Cervoni L, Celli P, Salvati M, Palma L. Supratentorial glioblastoma in children: a series of 27 surgically treated cases. Childs Nerv Syst. 1993:9:7-9.

5. Harbaugh KS, Black PM. Strategies in the surgical management of malignant gliomas. Semin Surg Oncol. 1998;14:26-33.
6. Johnson BE, Mazor T, Hong C, Barnes M, Aihara K, McLean CY, et al. Mutational analysis reveals the origin and therapy-driven evolution of recurrent glioma. Science. 2014;343:189-93.

7. Brennan CW, Verhaak RG, McKenna A, Campos B, Noushmehr H, Salama SR, et al. The somatic genomic landscape of glioblastoma. Cell. 2013;155:462-77.

8. Patel AP, Tirosh I, Trombetta JJ, Shalek AK, Gillespie SM, Wakimoto H, et al. Single-cell RNA-seq highlights intratumoral heterogeneity in primary glioblastoma. Science. 2014;344:1396-401.

9. Ferreira LM. Cancer metabolism: the Warburg effect today. Exp Mol Pathol. 2010;89:372-80.

10. Seyfried TN, Mukherjee P. Targeting energy metabolism in brain cancer: review and hypothesis. Nutr Metab (Lond). 2005;2:30.

11. Seyfried TN, Flores R, Poff AM, D'Agostino DP, Mukherjee P. Metabolic therapy: a new paradigm for managing malignant brain cancer. Cancer Lett. 2014;356:289-300.

12. Seyfried TN, Flores RE, Poff AM, D'Agostino DP. Cancer as a metabolic disease: implications for novel therapeutics. Carcinogenesis. 2014;35:515-27.

13. Warburg O. On the origin of cancer cells. Science. 1956;123:309-14.

14. Warburg $\mathrm{O}$. On the respiratory impairment in cancer cells. Science. 1956;124:269-70.

15. Kiebish MA, Han X, Cheng H, Chuang JH, Seyfried TN. Cardiolipin and electron transport chain abnormalities in mouse brain tumor mitochondria: lipidomic evidence supporting the Warburg theory of cancer. J Lipid Res. 2008;49:2545-56

16. Arismendi-Morillo GJ, Castellano-Ramirez AV. Ultrastructural mitochondrial pathology in human astrocytic tumors: potentials implications pro-therapeutics strategies. J Electron Microsc (Tokyo). 2008;57:33-9.

17. Deighton RF, Le Bihan T, Martin SF, Gerth AM, McCulloch M, Edgar JM, et al. Interactions among mitochondrial proteins altered in glioblastoma. J Neurooncol. 2014;118:247-56.

18. Oudard S, Boitier E, Miccoli L, Rousset S, Dutrillaux B, Poupon MF. Gliomas are driven by glycolysis: putative roles of hexokinase, oxidative phosphorylation and mitochondrial ultrastructure. Anticancer Res. 1997;17:1903-11.

19. Sipe JC, Herman MM, Rubinstein L. Electron microscopic observations on human glioblastomas and astrocytomas maintained in organ culture systems. Am J Pathol. 1973;73:589-606.

20. Cahill Jr GF, Veech RL. Ketoacids? Good medicine? Trans Am Clin Climatol Assoc. 2003:114:149-61. discussion 162-143.

21. Krebs HA, Williamson DH, Bates MW, Page MA, Hawkins RA. The role of ketone bodies in caloric homeostasis. Adv Enzyme Reg. 1971:9:387-409.

22. Veech RL, Chance B, Kashiwaya Y, Lardy HA, Cahill Jr GF. Ketone bodies, potential therapeutic uses. IUBMB Life. 2001;51:241-7.

23. Fine EJ, Miller A, Quadros EV, Sequeira JM, Feinman RD. Acetoacetate reduces growth and ATP concentration in cancer cell lines which over-express uncoupling protein 2. Cancer Cell Int. 2009;9:14.

24. Klement RJ, Kammerer $\mathrm{U}$. Is there a role for carbohydrate restriction in the treatment and prevention of cancer? Nutr Metab. 2011:8:75.

25. Seyfried TN, Kiebish M, Mukherjee P, Marsh J. Targeting energy metabolism in brain cancer with calorically restricted ketogenic diets. Epilepsia. 2008;49 Suppl 8:114-6.

26. Goetsch VL, Wiebe DJ, Veltum LG, Van Dorsten B. Stress and blood glucose in type II diabetes mellitus. Behav Res Ther. 1990;28:531-7.

27. Nebeling LC, Miraldi F, Shurin SB, Lerner E. Effects of a ketogenic diet on tumor metabolism and nutritional status in pediatric oncology patients: two case reports. J Am Coll Nutr. 1995;14:202-8.

28. Zuccoli G, Marcello N, Pisanello A, Servadei F, Vaccaro S, Mukherjee P, et al. Metabolic management of glioblastoma multiforme using standard therapy together with a restricted ketogenic diet: Case Report. Nutr Metab (Lond). 2010;7:33.

29. Seyfried TN, Sanderson TM, El-Abbadi MM, McGowan R, Mukherjee P. Role of glucose and ketone bodies in the metabolic control of experimental brain cancer. Br J Cancer. 2003;89:1375-82.

30. Zhou W, Mukherjee P, Kiebish MA, Markis WT, Mantis JG, Seyfried TN. The calorically restricted ketogenic diet, an effective alternative therapy for malignant brain cancer. Nutr Metab (Lond). 2007;4:5.

31. Abdelwahab MG, Fenton KE, Preul MC, Rho JM, Lynch A, Stafford P, et al, The ketogenic diet is an effective adjuvant to radiation therapy for the treatment of malignant glioma. PLoS One. 2012;7:e36197.

32. Shelton LM, Huysentruyt LC, Mukherjee P, Seyfried TN. Calorie restriction as an anti-invasive therapy for malignant brain cancer in the VM mouse. ASN Neuro. 2010;2:e00038. 
33. Fine EJ, Segal-Isaacson CJ, Feinman RD, Herszkopf S, Romano MC, Tomuta $\mathrm{N}$, et al. Targeting insulin inhibition as a metabolic therapy in advanced cancer: a pilot safety and feasibility dietary trial in 10 patients. Nutrition. 2012;28:1028-35.

34. Klement RJ. Calorie or carbohydrate restriction? The ketogenic diet as another option for supportive cancer treatment. Oncologist. 2013;18:1056.

35. Klement RJ, Champ CE. Calories, carbohydrates, and cancer therapy with radiation: exploiting the five R's through dietary manipulation. Cancer Metastasis Rev. 2014;33:217-29.

36. Longo VD, Mattson MP. Fasting: molecular mechanisms and clinical applications. Cell Metab. 2014;19:181-92

37. Raffaghello L, Safdie F, Bianchi G, Dorff T, Fontana L, Longo VD. Fasting and differential chemotherapy protection in patients. Cell Cycle. 2010;9:4474-6.

38. Woolf EC, Scheck AC. The ketogenic diet for the treatment of malignant glioma. J Lipid Res. 2015;56:5-10.

39. Willemsen MA, Soorani-Lunsing RJ, Pouwels E, Klepper J. Neuroglycopenia in normoglycaemic patients, and the potential benefit of ketosis. Diabet Med. 2003;20:481-2.

40. Maalouf M, Rho JM, Mattson MP. The neuroprotective properties of calorie restriction, the ketogenic diet, and ketone bodies. Brain Res Rev. 2009;59:293-315.

41. Seyfried TN. Ketone strong: emerging evidence for a therapeutic role of ketone bodies in neurological and neurodegenerative diseases. J Lipid Res. 2014:55:1815-17.

42. Meidenbauer JJ, Ta N, Seyfried TN. Influence of a ketogenic diet, fish-oil, and calorie restriction on plasma metabolites and lipids in C57BL/6 J mice. Nutr Metab. 2014;11:23.

43. Rieger J, Bahr O, Maurer GD, Hattingen E, Franz K, Brucker D, et al. ERGO: a pilot study of ketogenic diet in recurrent glioblastoma. Int J Oncol. 2014:44:1843-52.

44. Champ CE, Palmer JD, Volek JS, Werner-Wasik M, Andrews DW, Evans JJ, et al. Targeting metabolism with a ketogenic diet during the treatment of glioblastoma multiforme. J Neurooncol. 2014;117:125-31.

45. Freeman JM, Kossoff EH. Ketosis and the ketogenic diet, 2010: advances in treating epilepsy and other disorders. Adv Pediatr. 2010;57:315-29.

46. Hartman AL, Vining EP. Clinical aspects of the ketogenic diet. Epilepsia. 2007:48:31-42.

47. Mantis JG, Centeno NA, Todorova MT, McGowan R, Seyfried TN. Management of multifactorial idiopathic epilepsy in EL mice with caloric restriction and the ketogenic diet: role of glucose and ketone bodies. Nutr Metab (Lond). 2004;1:11.

\section{Submit your next manuscript to BioMed Central and take full advantage of:}

- Convenient online submission

- Thorough peer review

- No space constraints or color figure charges

- Immediate publication on acceptance

- Inclusion in PubMed, CAS, Scopus and Google Scholar

- Research which is freely available for redistribution 